\title{
Potrošačka kultura i ekonomija identiteta
}

\section{Potrošački mentaliteti i interdisciplinarna približavanja}

\author{
Lucija Mihaljević*, Borna Jalšenjak**
}

\begin{abstract}
Sažetak
Rad predstavlja doprinos raspravama o potrošačkoj kulturi u hrvatskom kontekstu. Uspoređujući paradigmu ekonomije identiteta kako se ona pojavljuje u ekonomskoj teoriji na prijelazu milenija, s antropološkim konceptima poput objektivizacije kulture, ukusa kao sredstva društvenoga razlikovanja i potrošnje kao izraza hijerarhije vrijednosti, ilustriraju se interdisciplinarna približavanja koja postuliraju klasičan kulturno-antropološki pojam identiteta u ekonomske analize. Na temelju narativnih empirijskih podataka prikazuje se kreativan karakter identifikacijskih procesa i nužnost pripisivanja performativnoga značenja ekonomskim praksama.
\end{abstract}

Ključne riječi: ekonomija identiteta, potrošačka kultura, procesi identifikacije, socioekonomska struktura, objektivizacija, robna kuća, trgovački centar

\section{Uvod}

Jedna od sveprisutnih metafora današnjice opisivanje je suvremenoga društva kao potrošačkoga društva. Iako je riječ o ekonomskim praksama, konceptualizacije društva kao potrošačkoga u dominantnoj su mjeri sociološke i antropološke. Riječ je o tome da, iako je svaki pojedinac naše povijesti trošio dobra koja je sam stvarao ili ih je za njega proizvodio netko drugi, suvremene potrošačke prakse karakterizira nadgradnja, odnosno ideološki višak, koji potrošačke obrasce tretira kao upute kako treba živjeti, odnosno kako uobličiti suvremene živote. U tom smislu potrošačka kultura označava da je hiperpotrošnja, odnosno konzumerizam, postao jedna od ključnih odrednica svakodnevice, čvrsto utisnuta u suvremene kulturne metafore. U prilog konzumerizmu kao dominantnoj odrednici suvremenoga doba svjedoči i mnoštvo raznorodnih znanstvenih i stručnih

* Dr. sc. Lucija Mihaljević, poslijedoktorandica na Hrvatskom katoličkom sveučilištu. Adresa: Ilica 242, 10000 Zagreb, Hrvatska. E-adresa: lucija.mihaljevic@unicath.hr

** Dr. sc. Borna Jalšenjak, viši predavač. Luxembourg School of Business; Zagrebačka škola ekonomije i managementa. Adresa: 19 Rue Eugene Ruppert L-2453, Luxembourg; Jordanovac 110, 10000 Zagreb, Hrvatska. E-adresa: bjalsen@zsem.hr 
radova koji modernu masovnu potrošnju analiziraju iz različitih perspektiva, od povijesnih istraživanja o potrošnji (Duda, 2010), preko ekonomskoga racionalizma (Gilboa, 2009) i sociološke kritike (Bauman, 2007), zatim antropološkoga strukturalizma (Bourdieu, 2011; Douglas i Isherwood, 1996) i teoretičara procesa (Miller, 1993) do bihevioralne ekonomije (Simone, 1955). Međutim, unatoč tomu što potrošnja jest označujući element svakodnevice suvremenoga društva, opći pregled studija i teoretičara potrošnje ne postoji. Razlog je tomu što su »studije potrošnje imale različite pristupe gotovo zbunjujućemu broju tema, sve postavljene unutar određenoga okvira disciplina, svaka s vlastitim procedurama i protokolima « (Miller et al., 1998, 2). ${ }^{1}$ Analiza koja slijedi na stranicama ovoga rada, analitički se inspirira upravo na paradigmatskoj multidisciplinarnosti potrošnje kao teme istraživanja, te novijim metodološkim pomacima u smjeru interdiciplinarnosti. U kontekstu metodološkoga približavanja naglasak je na antropologizaciji, odnosno humanizaciji ortodoksnih ekonomskih modela. Naime, jedan od recentniji interdisciplinarnih pomaka predstavlja model ekonomije identiteta (eng. identity economics) postuliran od strane nobelovca ekonomista Georgea Akerlofa (Akerlof i Kranton, 2012). Iako već na nominalnoj razini taj model otkriva humanizaciju ekonomske teorije, ključan analitički pomak sastoji se u prihvaćanju antropološkoga koncepta identiteta među ekonomistima (Akerlof i Kranton, 2012, 113) te afirmaciji etnografije kao relevantne i bitne metode ekonomske istraživačke prakse. Kako to opisuju sami začetnici ideje, ekonomija identiteta »uvela [je] društveni kontekst [u ekonomiju] — s novim muškarcem i ženom, koji nalikuju na stvarne ljude u stvarnim situacijama « (Akerlof i Kranton, $2012,7)$. Inspirirani navedenim interdisciplinarnim prepoznavanjem, odnosno humanizacijom ortodoksnih ekonomskih modela, namjera je prikupljenu empirijsku etnografsku građu o potrošačkim praksama i iskustvima sagledati u perspektivi novih metodoloških pomaka u smjeru interdisciplinarnoga tumačenja potrošačkoga društva.

\section{Interpretativni okvir}

Povijesno gledano, potrošnja je kao istraživačka tema dugo bila potiskivana na rub gotovo svih disciplina društvenih znanosti. Razlog je tomu analitičke naravi. Riječ je o dominantno produktivističkoj viziji moderniteta, koja je do druge polovice 20. stoljeća značila da temeljne faktore u oblikovanju društvenoga života predstavljaju iskustva i odnosi povezani s radom (Čolić, 2008, 954). S obzirom na to, problematiziranje moderne potrošnje zahtijevalo je preispitivanje osnovnih teorijskih, epistemoloških i metodoloških pretpostavki svake od disciplina (Miller, 1995). Na tom tragu tematiziranje potrošnje u okviru antropološke teorijske paradigme značilo je prihvaćanje novih, hibridnih kultura modernosti, bez jasne kulturne drugosti, a etnografsko pisanje prihvatilo se kao teorijski stav

1 Citati preuzeti iz izvornika na stranim jezicima prijevod su autora članka. 
(Miller, 1994; Erdei, 2008). Za ekonomiju taj se disciplinaran pomak događa na prijelazu milenija pojavom spomenutoga modela ekonomije identiteta, koji označava uvođenje kategorije identiteta, razumijevanoga kao osobni doživljaj sebstva, u ekonomske analize. Točno je, međutim, da se ortodoksna ekonomija djelomično "otvarala" i ranijih desetljeća, postepeno prihvaćajući kognitivan model ograničene racionalnosti (Simon, 1955). Prepoznavanje motivacija koje nadilaze načelo korisnosti, dakako, poznato je, priznato i prakticirano u sferi marketinškoga komuniciranja (Martinović, 2012). No, pionirski tekst antropološkoga zaokreta u okviru ekonomske profesije objavljen je 2000. godine u Quarterly Journal of Economics pod naslovom Economics and Identity, u autorstvu nobelovca ekonomista George Akerlof i njegove suradnice Rachel Kranton (Akerlof i Kranton, 2000). Iako iz kulturno-antropološke i filozofske perspektive povezivanje identiteta i ekonomskih praksi nije nova ideja, uvođenje identiteta kao kategorije u formalne ekonomske analize značilo je stvaranje nove paradigme u okviru ekonomske teorije, odnosno napuštanje ideje kako se individualni izbor različitih roba i usluga utemeljuju samo na klasičnom ekonomskom načelu korisnosti, tradicionalnom ključu za opisivanja motivacija ekonomskih praksi. $\mathrm{Na}$ ovaj način predstavljeno, antropologizirano tumačenje ekonomske prakse potrošnje moglo bi se činiti kao "idealna" simbioza teorijsko-istraživačkih perspektiva s tržišno-profitno motiviranim interesima tvrtki. Međutim, iako možda tomu i jest tako iz perspektive korporativnoga miljea, socio-antropološke analize potrošnje ukazuju na kritičke odmake spram spomenute simbioze. U tom kontekstu bitno je istaknuti kako je Philip Kotler, najutjecajniji suvremeni autor iz područja marketinga, još u svojim ranim radovima pisao o marketingu kao društvenom procesu (Kotler, 1967), te isticao da se društvene kritike marketinga odnose na hiperpotrošnju (Kotler, 1972). Međutim, društvena kritika koju Kotler prepoznaje sastoji se u makroperspektivi, u razvoju društvene odgovornosti marketinga. ${ }^{2}$ Nasuprot tomu, iz antropološke, mikroperspektive, riječ o preispitivanju dominantnoga društvenoga identiteta potrošačke kulture "biti potrošačem”, koji postaje temelj koncepta slobode u suvremenom društvu (Miles, 2006). Ključan problem sastoji se u tome što je taj tip slobode prisilan, s obzirom na to da »biti potrošačem ideološko je pravo stečeno rođenjem zapadnoga modernoga subjekta «(Slater prema Čolić, 2008, 957). ${ }^{3}$ Što se utemeljuje na bitku potrošačke kulture, koju »karakterizira društveno uređenje u kojem se odnos između življene kulture i društvenih resursa, između svrhovitih načina života i simboličkih i

2 Budući da je ovaj članak interdisciplinarnoga karaktera, bitno je također istaknuti kako je termin konzumerizam dvojakoga značenja. Naime, uz uvodno definiran teorijsko-analitički pristup tumačenja konzumerizma kao ideološkoga viška, u ekonomskoj literaturi pojavljuje se njegova definicija u nešto drugačijoj perspektivi. Prema Kotleru, konzumerizam je »društveni pokret koji nastoji povećati prava i snagu kupaca u odnosu na prodavače« (Kotler, 1972, 49). Pritom se nastoji naglasiti odgovornosti prema potrošaču i društvu, iz čega on dalje razvija teoriju društvenoga marketinga, odnosno marketinga usmjerenoga na društvo (eng. societal marketing).

3 Tematski broj časopisa Društvena istraživanja iz 2008. naslovljen je Potrošačka kultura i tržišno društvo. Također, 2013. objavljen je prvi domaći zbornik radova posvećen temi potrošačke kulture pod naslovom Potrošačka kultura i konzumerizam (Čolić, 2013). 
materijalnih resursa o kojima oni ovise, posreduje kroz tržište « (Slater prema Čolić, 2008, 957). Ekspresivne dimenzije potrošačke kulture ujedinjuju se u »reprezentima potrošačkoga društva« (Stanić, 2013), suvremenim trgovačkim centrima, koji pak postaju terenom akademskih analiza. Riječ je o tome da je pojava novih potrošačkih prostora potaknula i vrlo specifičnu promjenu potrošačke svijesti i potrošačkih praksi. Naime, ideja trgovačkoga centra utemeljena je na ideji natkrivenoga grada, ${ }^{4}$ gdje su svi komercijalni i rekreativni sadržaji smješteni pod istim krovom, a ne u istim ulicama (Falk i Campbell, 1997, 9). Utoliko je materijalizaciju potrošačke kulture, trgovačke centre, moguće pojmiti kao mallizaciju društva. ${ }^{5}$

Isti fenomen zahvatio je i hrvatskoga potrošača, međutim, poradi socijalističkoga razdoblja, gotovo pola stoljeća kasnije nego li u zapadnoj Europi i SAD-u. Ipak, u Hrvatskoj je i u doba socijalizma, kada još nije bilo takvih blještavih trgovačkih centara, postojao potrošački prostor u kojem se moglo kupiti sve pod jednim krovom - u ondašnjem lancu robnih kuća Narodni magazin, popularno zvanom akronimom Nama. Nama Card nudila je opciju kupovine na rate na deset zagrebačkih prodajnih mjesta te 1970. godine ostvarivala $21 \%$ ukupnoga maloprodajnoga prometa u Zagrebu (Gavranović, 1971, 58). ${ }^{6}$ Relevantna literatura širokoga spektra, kako ona antropološka, tako i ona iz područja menadžmenta, robne kuće definira pretečama trgovačkih centara (Chaney, 1983). Na dijakronijskoj kompatibilnosti robnih kuća i trgovačkih centara utemeljuje se analitika ovdje izloženoga tumačenja. Fokus je na suodnosu potrošačkoga prostora, praksi koje se uz njega vežu te simboličko značenje koje nosi u različitim društvenoekonomskim razdobljima. ${ }^{7}$ Naime, ako se mallizacija društva označava kao jedan od »manifestacijskih fenomena tranzicije postkomunističkih društava« (Hromadžić, 2008, 68), logično je, zanimajući se za ekonomiju identiteta, potražiti usporediv analitički prostor u vremenu prije trgovačkih centara, u vremenu drugačije svijesti, normi, vrijednosti i poželjnih ponašanja (Erdei, 2012). Teorijski se analiza prikupljene građe utemeljuje na dvije perspektive: na antropološkom strukturalizmu u kojem ukus postaje obrazac društvenoga razlikovanja (Bourdieu, 2011), a potrošnja izraz hijerarhije vrijednosti (Douglas i Isherwood, 1996), te na teorijskoj perspektivi objektivizacije kulture, koja se sastoji u načinu na koji pojedinci i grupe objektiviziraju svoje vrijednosti i sebe same, koristeći se materijalnom kulturom i potrošačkim aktivnostima (Miller, 1993), uzimajući u obzir

4 Prvi trgovački centar otvoren je 1956. u Edini, predgrađu grada Minnesote, a osmislio ga je austrijski arhitekt Victor Gruen.

5 Termin mallizacija, iako je prisutan (Stanić, 2013, 15), nije još uvriježen u socio-antropološkoj literaturi.

6 Trgovinska radna organizacija Narodni Magazin utemeljena je 12. lipnja 1945. odredbom Privrednoga savjeta Demokratske Federativne Jugoslavije uvođenjem radničkoga samoupravljanja.

7 Važno je napomenuti kako je današnja robna kuća Nama, u Ilici br. 4, svoja vrata otvorila još davne 1913. pod imenom Kastner i Öhler, te utoliko predstavlja najstariji potrošački prostor u Zagrebu koji je nudio sve pod jednim krovom. Nakon rata je nacionalizirana 5. rujna 1945. presudom Suda za zaštitu nacionalne časti Hrvata i Srba u Hrvatskoj te "preuzeta" od strane novo uspostavljene organizacije Zemaljske podružnice za narodnu Republiku Hrvatsku državnoga trgovačkoga poduzeća Narodni magazin (Gavranović, 1971, 5). 
globalni kontekst. Taj kulturno-antropološki teorijski okvir, analizirajući empirijsku građu, uspoređujemo s opisanom teorijom i idejama ekonomije identiteta.

\section{Metodologija}

Etnografsku građu predstavljaju transkripti polustrukturiranih dubinskih intervjua, dviju fokus grupa, ${ }^{8}$ bilješke sesija etnografskoga opažanja, arhivsko gradivo prikupljeno u Muzeju grada Zagreba i većim dijelom iz privatnih zbirki te medijski članci prikupljeni iz dnevnih tiskovina i Internet portala. Iako se u ovom radu izlaže prvenstveno narativna građa, istraživačka promišljanja inspirirana su na cjelokupnom etnografskom opusu. S obzirom na induktivan karakter kvalitativnih istraživanja koji pretpostavlja fleksibilnost "prihvaćanja metoda koje omogućavanju unapređenje ideja u nastajanju « (eng. emerging ideas) (Charmaz, 2006, 16), novu perspektivu tumačenja ranije prikupljenih podataka potaknula je i multidisciplinarna literatura koju smo upoznali. ${ }^{9}$ Posebno ona koja se izravno ili neizravno dotiče ekonomije identiteta, odnosno afirmira antropološke koncepte i metode u ekonomskim istraživanjima i raspravama (Akerlof i Kranton, 2000; Akerlof i Kranton, 2012; Davis, 2011; Garai, 2016).

Sukladno uvriježenoj praksi kvalitativnih istraživanja, pristup analizi podataka je induktivan te temeljen na pravilima »etnografski utemeljene teorije « (Charmaz, 2006; Čapo Žmegač et al., 2006), pri čemu se teorijsko tumačenje gradi na temelju prikupljenoga empirijskoga gradiva. Sukladno tomu, riječ je o interpretaciji potrošačkih praksi onako kako se one oblikuju u narativima sudionika istraživanja, smještajući taj sadržaj u širi društveni kontekst političkih i ekonomskih promjena u Hrvatskoj. Citirani etnografski materijal čini integralnu cjelinu interpretacije te prilikom izlaganja nije korišten samo kao ilustracija i potvrda zaključaka, nego analitički postupak čini transparentnim, a čitatelja potiče na pomnije promišljanje. Individualne potrošačke prakse tumačene su kao sustav značenja i simbolični čin, a prostor Name kao antropološko mjesto (Augé, 2001), simboličan i identifikacijski potrošački prostor, odnosno kao mjesto prakse (Certeau, 2003). Svoju konceptualizaciju Certeau sažeto formulira riječima: »prostor je prakticirano mjesto « (eng. space is a practiced place, franc. l'espace est un lieu pratiqué) (Certeau, 2003, 183). Upravo na Certeuova tumačenja prostora kao mjesta prakse utemeljujemo metodološko opravdanje za izbor trgovačkoga prostora kao arene za usporedivu interpretaciju potrošačke svijesti i s njima povezanih identifikacijskih procesa u različitim socioekonomskim i političkim razdobljima u Hrvatskoj.

8 Dio gradiva prikupljen je tijekom doktorskoga istraživanja prvoga autora 2013., koje je u naknadnom razdoblju nadopunjeno dvjema fokus grupama sa studentima, što ukupno obuhvaća 44 kazivačice i kazivača u dobi od dvadeset dvije do osamdeset sedam godina, u trenutku provođenja intervjua, te 13 studenta u drugoj fazi istraživanja u dobi od 20 do 24 godine. U istraživanju su poštovani etički uzusi dobrovoljnoga i informiranoga sudjelovanja te anonimnosti podataka.

9 Kroz suradnju na Katedri za marketing, pripremi novih kolegija te sudjelovanju na konferencijama. 


\section{Društveni kontekst potrošnje i variranje ukusa}

Kada je riječ o potrošnji u socijalističkom razdoblju u Hrvatskoj, Nama je sveprisutna, kako na razini neformalnih rasprava, poput blogova i tekstova na internetskim portalima, ${ }^{10}$ tako i na razini novinarskih komentara ${ }^{11}$ i povijesnih istraživanja potrošačke kulture u Hrvatskoj (Duda, 2010, 39). Diskurs dominantno obiluje usporedbom ondašnjih (socijalističkih) Nama s današnjim trgovačkim centrima. Kako u jednom od blogova autorica opisuje: »U našem je djetinjstvu robna kuća imala posebno značenje. Svaki grad je imao svoju robnu kuću, jednu ili više njih. To su bila mjesta gdje smo žudjeli otići s roditeljima [...] koje su ipak bile socijalistički raj za kupce« (Vlaović, 2018). Svi sudionici ovoga istraživanja srednje i starije dobi potvrdili su upravo navedeno — da je u doba Jugoslavije Nama za njih bila neizostavno mjesto potrošnje. Riječi jednoga od sugovornika opisuju "status" Name u ono doba na posebno slikovit način. Naime, prisjećajući se Name u doba svoje mladosti, sugovornik je istaknuo kako je sedamdesetih godina prošloga stoljeća Nama bila "kultna":

Onda se tamo češće kupovalo, da, puno više, Nama je bila kultna. Ne samo išel sam u kupnju, išel sam u Namu. Ovoga ja sad sebe izdvajam, gledam ono s aspekta kak sam ja to videl, da je to bil izlet, od prvog kata do petog kata, znači dole si. Ljudi su dole vidli ove bombone, onda su išli na kat di je posuđe, onda su išli di je obleka, na kraju su završili tam di su tepisi i tak dalje, znači to je bila ko jedna šetnja, procedura, uvijek se nekaj kupilo, ali se, ko na nekakvom, šta ja znam, korzu, i ti kad si ušla u ono vreme u Namu, nije bilo slobodnog prostora, Nama je bila puna, uvijek si se sudaral s nekim, razmeš, zato su i džepari dobro i funkcionirali, kad je bila gužvica [...] Ipak je to bil centar grada, tu se nešto odvijalo, i onda ti je izlazak, ne, tam se može izići. Znači, idemo van, i automatski te noge vode šetnjom u Namu, i tak, to ti je izlazak, kak danas idu u šoping centar. [...] Da, kak danas zgleda, tak su išli u Namu, a danas, vidiš kad uđeš u Namu je prazno (M, 51).

To je kazivanje u skladu s ostalim narativnim materijalom koji ističe nekoliko općih karakteristika korištenja Name u jugoslavenskom razdoblju. Kao prvo, svi sudionici srednje i starije dobi opisali su kako je u to vrijeme Nama "bila puna", odnosno da je ondje redovito bila gužva, te kako se »u Nami kupovalo sve«. Takvi opisi ukazuju na to da su se u Nami u doba socijalizma ostvarivale prakse rekreativne potrošnje slične onima u današnjim trgovačkim centrima. Termin rekreativna potrošnja temelji se na dvije takozvane potrošačke orijentacije "kupovanje za" (eng. shopping for) i "kupovanje okolo" (eng. shopping around) (Falk i Campbell, 1997, 5-6), koje se teorijski utemeljuju na namjeri razlikovanja modernizacijske distinkcije nove potrošačke kulture naspram tradicionalnih potrošačkih praksi. Naime, u praksi rekreativna potrošnja (eng. shopping around)

10 Nama je kao tema prisutna u okviru raznih amaterskih blogova, a posebice onih koji su posvećeni potrošnji u socijalizmu i povijesti grada Zagreba (usp. Žimbrek, 2017).

11 Nakon članka u Jutarnjem listu 14. srpnja 2013. Nama se gasi, u dnevnim novinama objavljeno je nekoliko kritičkih osvrta na tu temu, međutim problematika je medijski relativno brzo zamrla, a sve do danas, status Name nije se promijenio. 
rijetko postoji u izoliranom, "čistom" obliku, jer se ona dominantno sastoji u preklapanju te rekreacije s ostalim rekreacijama u gradu — bio on, kako ćemo vidjeti u redcima koji slijede, "otvorenoga" ili "zatvorenoga" tipa. Naime, kazivanja o kupovini u Nami često su isprepletena s opisima kupovine u drugim trgovinama. Kazivači su istovremeno govorili i o tome što nisu kupovali u Nami i/ili što ne bi kupili u Nami danas.

Kupovali smo, al svašta smo kupovali u Nami pošto stvarno uvijek, znači kupovali smo od nekoga sitnoga namještaja, lampi, ovih potrepština kućnih, žarulja tih starih, gaća, čarapa, ponekad neki odjevni predmet al u smislu trenirke il nečeg. Nismo baš išli u šoping u Namu, tipa ja idem u Namu kupit si novo odijelo ili znači nešto, jaknu il nešto što, što baš ciljam. Onda bi išo u neki od ovih što sam prije govorio dućana, u neki koji sam prije govorio, ne bi išo u Namu. Ali često kupujemo u Nami što zbog, isključivo zbog praktičnosti jer nam je blizu, i sa svjesnošću da je Nama strahovito skupa (M,28).

Riječ je upravo o distinkciji kupovine i “šopinga": »nismo baš išli u šoping u Namu « naspram »ali često kupujemo u Nami«, koja prevladava u prikupljenim podatcima. Ako ljudi razlikuju potrošačku praksu kupovine određenih predmeta naspram prakse kupovine drugih, možemo li zaključiti da postoji razlika između korisnih predmeta svakodnevne uporabe (sitnoga namještaja, žarulja, gaća, čarapa) od predmeta kao sredstva razlikovanja (Bauman, 1988, 808), kojima se pojedinac prikazuje drugima (Veblen, 2008), poput novoga odijela. Utilitaran karakter kupovine u Nami potvrđuju i kazivanja turista koji su postali dijelom istraživanja u okviru sesija etnografskoga opažanja robne kuće, te u fokus grupi sa studentima. Oni su redom isticali kako bi svakako ponovno došli u Namu da im nešto ustreba, ali da ne bi ondje kupovali odjeću jer preferiraju svoje marke kojih u Nami nema. Brend kultura razumijevana kao kultura u kojoj vrijednost marke predstavlja ključno sredstvo kategorizacije i klasifikacije roba, pa posljedično i imidža, odnosno identiteta i društvenoga pozicioniranja onih koji ih koriste, također je tekovina potrošačkoga društva. Međutim, iako narativni materijal izrazito sadržava opise poput navedenih, kako se u Namu »ne ide kupiti odijelo«, važno je napomenuti da se ona u Nami i danas nude i prodaju. Utoliko bismo mogli marketinškim rječnikom zaključiti kako svaka roba ima svojega kupca. Međutim, iz filozofske i antropološke perspektive, čini se da je potrošačka svijest suvremenih Naminih kupca nešto drugačija te da ondje odjeću kupuju oni kojima snaga brenda ne predstavlja važan element osobnoga identiteta.

Dok smo kupovali rolšuhe ugledala na tom športskom odjelu neki gornji dio trenirke, hrvatski proizvod, a firma se zove otprilike $[\ldots]$ znaš ono nešto $[. .$.$] nemam pojma,$ nekakvo kretensko ime. [...] Zahvaljujući tome što moje dijete nema nikakav odnos spram firmiranom, njoj se to svidilo, bilo je na sniženju $110 \mathrm{kn}$, obično je preko 200 kuna gornji dio trenirke crveni, čisti pamuk pa smo uzeli, tak da... kao što je Marija [prijateljica] ušla i otkrila da za njene gabarite ima ono, zgodne oprave $(\check{Z}, 50)$.

Takva kazivanja nameću pitanje jesu li individualni potrošački identiteti, neopterećeni snagom branda, dio nasljeđa tradicije i prošlosti, u tom slučaju socijalističke, kada je brand kultura bila manje prisutna nego danas. Ili je možda riječ 
o osobnom svjetonazoru, odnosno svjesnom i proaktivnom odbijanju ideološkoga višaka potrošačke kulture? Komentar sugovornice otkriva nekoliko razina problematike Name kao mjesta prakse. Kao prvo, to kazivanje govori u prilog neodvojivosti potrošačkih orijentacija ciljane i rekreativne potrošnje (shopping for i shopping around), čak i u prostorima koji su primarno percipirani kao mjesta korisne potrošnje. S druge strane, ukazuje kako prakticiranje Name ovisi o vrijednosnim kategorijama pojedinca. Nije riječ o tome da određeni predmeti jesu bitnije gradivo subjektiviteta, a drugi manje bitno, nego da ne postoji univerzalna klasifikacija, odnosno da je proces objektivizacije zavisan od individualnih stavova i ukupnoga habitusa (Bourdieu, 2011). ${ }^{12}$ Stoga, bez obzira na prevladavajuću praksu korištenja Name, nije moguće govoriti o prakticiranju toga potrošačkoga prostora u univerzalnim terminima, odnosno tvrditi da model korisnosti isključuje proces objektivizacije. Prema Douglas i Isherwoodu »ideju racionalnoga pojedinca nije moguće apstrahirati iz društvenoga života« jer su »apstraktni koncepti uvijek teško pamtljivi, sve dok ne poprime neku fizičku pojavu « (Douglas i Isherwood, 1996, VIII). Međutim, ono što strukturalističkomu poimanju potrošačkih praksi ipak nedostaje osjetljivost je za proces objektivizacije, odnosno procesualan karakter pripisivanja specifičnih značenja materijalnim objektima uslijed njihova korištenja (kroz praksu), na individualnoj razini (Miller, 1993). Proces izgradnje subjektiviteta ne znači samo prisvajanje novih značenja korištenjem predmeta koji prenose prethodno konstituirana simbolička značenja, poput brendirane odjeće. Proces objektivizacije, odnosno izgradnja vlastitoga identiteta pomoću materijalnih objekata performativnoga ${ }^{13}$ je karaktera te se odvija i odbijanjem ili jednostavno nekorištenjem proizvoda s potpisom. Odnosno, kako to opisuje Miller, proces objektivizacije stupnjevitoga je karaktera, u kojem prvi stupanj uključuje proizvodnju i kulturnu klasifikaciju predmeta, kako bi se zatim na drugoj razini ti označeni predmeti povezali s određenim životnim stilom. U tom smislu, također, ukoliko su proizvodi koji se prodaju u Nami u prvoj fazi klasificirani kao korisni, utoliko u drugoj fazi oni postaju simbolima individualnih identiteta — kako onih koji ih koriste, tako i onih koji ih odbijaju. Time potrošnja postaje gradivo subjektiviteta neovisno o tom je li ekonomska transakcija realizirana ili nije (Miller, 1995, 16).

Ako izložene analize sučelimo s ekonomskim konceptom ekonomije identiteta, bitno je prisjetiti se kako je načelo korisnosti u okviru ortodoksne ekonomske teorije dominantno monetarizirano, što znači da je većina ekonomskih analiza usredotočena na novčane motivacije u primarno dvije kategorije — želja

12 Prema Bourdieu habitus predstavlja sustav trajnih i prenosivih dispozicija, odnosno prethodnih iskustava, koja usmjeravaju praktično djelovanje (i rasuđivanje) pojedinca (Bourdieu, 2011, 180).

13 Od eng. perform, izvoditi, provoditi, činiti. Značenje termina performativno proizlazi iz filozofije jezika te upućuje na procesualan karakter određenih iskaza kojima se ne može ustvrditi istinitost jer ovise o danim, odnosno specifičnim uvjetima. Nasuprot performativa su konstativi, koji predstavljaju sudove kojima se nešto utvrđuje, opisuje, konstatira, te mogu biti istiniti ili ne. Upravo takva dinamika performativnosti, kao kontekstualnoga značenja i istinitosti, primjenjiva je i na ovdje istraživanoj temi. 
za prihodom i želja za potrošnjom (Akerlof i Kranton, 2012, 10). Prihvatiti takvo stajalište znači zanemariti činjenicu kako je ono do čega je ljudima stalo, i u kojoj mjeri, bitno definirano njihovim identitetom. Ekonomija identiteta nastoji nadići ortodoksno ekonomsko shvaćanje, definirajući identitet na antropologičniji način: »Identitet ljudi određuje tko su oni — njihovu društvenu kategoriju « (Akerlof i Kranton, 2012, 13), pri čemu se društvena kategorija odnosi na način kako pojedinac sebe vidi u danom vremenu. Odnosno antropološkim rječnikom rečeno, s obzirom na proces samoidentifikacije. Društvena je kategorija za ekonomiste identiteta definirana normama te pokretljiva, jer tijekom životnoga vijeka ljudi mogu dramatično mijenjati svoja shvaćanja. Iz kulturno-antropološke perspektive riječ je o dinamici identifikacijskih procesa na longitudinalnoj razini.

Kulturni antropolog, kojega Akerlof i Kranton, začetnici ideje ekonomije identiteta, opisuju kao »profesionalnoga promatrača identiteta, normi i vrijednosti « (Akerlof i Kranton, 2012, 6), navedenu interpretaciju vrlo lako prepoznaje. Dapače, većina od navedenoga doima se inspirirana na idejama strukturalističke antropologije potrošnje (Bourdieu, 2011; Douglas i Isherwood, 1996),${ }^{14}$ odnosno s njima korespondira. Da je ekonomija identiteta dominanto strukturalistička ontološka opcija, potvrđuje i njihova konceptualizacija identiteta koji definiraju kao: (1) povezivanje pojedinca s društvenim kategorijama, (2) prepoznavanje normi i identiteta pripadajućih kategorija te (3) detektiranje dobitaka i gubitaka u identitetskoj korisnosti. ${ }^{15}$ Želeći naglasiti društveni kontekst, ekonomisti identiteta govore o ekonomiji ukusa »u kojoj ukusi variraju prema društvenom kontekstu« te »identiteti i norme proizlaze iz društvene sredine« (Akerlof i Kranton, 2012, 6). Čime afirmiraju socio-antropološko teorijsko tumačenje potrošnje kao ideološki, a ne samo monetaran sadržaj. Međutim, kako će biti prikazano u poglavlju koje slijedi, još uvijek ne uviđajući relevantnost kulturne klasifikacije predmeta, odnosno procesa objektivizacije, kao snage djelujućega pojedinca za izlazak iz struktura.

\section{Potrošačka lokacija i identifikacija}

Argumentacija o variranju ukusa s obzirom na društveni kontekst nije zanemariva i može se primijeniti i na slučaj izostanaka rekreativnoga korištenja Name u najnovije doba: »danas vidiš, kad uđeš u Namu je prazno« (M, 51). Upitani o izgledu užega centra Zagreba, a posebice trgovačke ulice Ilice, u svojoj mladosti i danas, svi su istaknuli kako danas ima »puno više žblještavih' dućana«. Nova potrošačka mjesta, blještavi dućani, izmijenili su urbani okoliš i postali svojevrstan izazov "staroj” Nami. No, čini se, ne samo njoj. Premještanje pejzaža potrošnje na rubne dijelove Zagreba, odnosno mallizaciju lokalne potrošačke kulture, po-

14 Na Bourdieua se Akerlofa i Kranton u svojoj knjizi Ekonomija identiteta iz 2010. godine, kojom afirmiraju tu ekonomsku teorijsko-metodološku novu paradigmu, referiraju, međutim u članku iz 2000. godine, kada tu ideju prvi puta izlažu, ne citiraju ga, kao ni Douglas.

15 Za ekonomiju identiteta identitetska korisnost predstavlja »dobitak kada su akcije usklađene s normama i idealima, i gubitak ako nisu « (Akerlof i Kranton, 2012, 18). 
tvrđuje i akcija tzv. Zagrebačke subote. Riječ je o strategiji uvođenja produženoga radnoga vremena subotom u trgovinama u centru grada, s ciljem oživljavanje užega središta grada upravo poticanjem potrošačkih praksi te brendiranjem Zagreba kao trgovačke metropole (Brstilo, 2014, 89). Ta je akcija pokrenuta 2009. godine, a praksa produljenoga radnoga vremena nastavila se do vremena pisanja ovoga rada, iako ne uključuje sve trgovine u centru grada. U tom kontekstu James Madison, analizirajući procese promjena urbane komercijalne kulture, ističe kako su širenjem gradova i razvojem predgrađa, robne kuće izgubile dominantnu ulogu »ne samo kao posljedica novih oblika maloprodaje, nego i zbog izmijenjene strukture grada « (Madison, 1976, 103). Može se zaključiti da se proces mallizacije i u hrvatskom slučaju odvijao istim smjerom. Međutim, ono ključno jest da se bez obzira na promijenjenu strukturu grada njegova živost nastoji povratiti upravo poticanjem potrošačkih praksi, što predstavlja još jednu potvrdu kulturološkom tumačenju potrošačkoga društva, koje podrazumijeva da primarna funkcija trgovačkoga prostora može poprimiti nova društvena značenja, odnosno da grad može poprimiti svojstva trgovačkoga centra na otvorenom. Riječ je zapravo o obrnuto proporcionalnom procesu koji se dogodio "seobom urbanoga konteksta" u predgrađe, odnosno o preslikavanju trgovačkoga centra na centar grada, što potvrđuje potrošačku kulturu kao bitnu odrednicu suvremene svakodnevice. Jedna od sudionica tu stvarnost opisala je vrlo je sažeto: »znaš kako se danas živi, popodne u šoping centru « $(\check{Z}, 39)$. Prema mišljenju sugovornika srednje dobi, neprirodnost urbano-potrošačkoga iskustva u modernim trgovačkim centrima predstavlja negativnu stanu potrošačke kulture u službi suvremenoga neoliberalnoga kapitalizma, a njihove naracije mogu se tumačiti kao slikoviti prikaz otuđenosti potrošačkoga društva danas:

Ti šoping centri su mi nekako, ti prostori mi ne odgovaraju, nema zraka, nikad ne znaš da li je noć ili dan, ne vidiš sunca ni mjeseca, nekako mi nije prirodno, više volim da sam na zraku, pa uđem, izađem, odem na neku kavicu. Znam da mogu ići na kavicu u šoping centru, ali mi je ljepše po gradu se muvati i tako. Ne znam, te šoping centre ne volim previše. Ali odem u šoping centar, ne mogu reć da ne idem nikad, nije točno, idem i ja. Zgodna stvar je što imaš u šoping centru sve na jednom mjestu i ne plaćaš parking, još je zgodno što možeš klinca staviti tamo u taj vrtić pa sat vremena si na miru, jer vuć klinca sat vremena po dućanima je noćna mora, tako da je njemu dobro, dobro je i nama, ali to se ne svodi na neko guštanje $(\check{Z}, 39)$.

To kazivanje potvrđuju kako mallizacija ne znači samo pojavu novih potrošačkih prostora, nego je riječ i o analitički relevantnoj preobrazbi potrošačkoga iskustva. Osim što ono nije izoliran slučaj, dapače i afirmativna kazivanja mlađih sugovornika koja opisuju zadovoljstvo korištenja trgovačkih centara redovito se dotiču osjećaja izvještačenosti u takvim prostorima. ${ }^{16}$ Ono čega se također uni-

16 Riječ je o atribuciji koja se specifično odnosi na područje senzornoga marketinga (Krishna, 2010), u kojem se tendenciozno nastoje obuhvatiti sva ljudska osjetila, poput uređivanja prodajnih prostora s ciljem da se kod kupca izgubi osjećaj za vrijeme. Komentar koji se pojavljuje u etnografskom materijalu, a koji se odnosi na to da se ne zna je li dan ili noć, primjer je navedenoga, te bi bio vrlo uobičajen kod klijenata u kockarnicama koje su uređene na taj način. 
verzalno dotiču jest redovito spominjanje automobila u takvim naracijama. Iz ekonomske perspektive u ovu bismo analizu sada uveli dvije kategorije — vlasnike automobila i one koji to nisu. Što je strukturalno u podatcima opravdano, s obzirom da i naše narativno gradivo pokazuje kako je posjedovanje automobila relevantno za analizu potrošačkoga identiteta u doba mallizacije društva, jer »moraš nekak do te ogromne zgradurine, tam negdje, tam Bogu iza nogu nekak doć« $(\check{Z}, 32)$. Naime, već iz upravo navedenoga iskaza očito je negodovanje spram kupovine u trgovačkom centru. No, nije riječ samo o odlasku na određena potrošačka mjesta, nego se uspoređujući potrošačke prakse onih koji se koriste javnim prijevozom naspram onih koji posjeduju vlastiti automobil mogu analizirati ne samo potrošački identiteti, nego i pojedinačni vrijednosni sudovi, odnosno rječnikom ekonomije identiteta — uključivanje identiteta i normi u razmatranje ekonomskih praksi stvara novu »teoriju o odlučivanju u kojoj je društveni kontekst bitan« (Akerlof i Kranton, 2012, 6).

Tiče se toga da je izbor potrošačkoga mjesta, osim praktičnosti, bitno obilježen osobnim životnim stilom, pa čak i simboličkim značenjima. Za primjer, trud onoga koji nema automobil da dođe do udaljenoga trgovačkog centra predstavlja svojevrsni potrošački poduhvat koji ne mora nužno biti utemeljen na praktičnoj potrebi, nego može biti riječ o subjektivnoj preferenciji pri izboru potrošačkoga mjesta, koja otkriva daleko više od samih potrošačkih praksi dotičnoga pojedinca. Isto tako, prakticiranje kupovine u trgovini ili na tržnici u centru grada, naspram odlaska u supermarket u blizini doma, otkriva individualne identifikacijske procese koji nadilaze potrošnju. Upitani jesu li mjesta potrošnje povezana s mjestom njihova stanovanja, sugovornici su razotkrivali upravo vlastite vrijednosne sustave i životne stilove.

Evo to mogu reći da sam u zadnjih nekoliko kupovina podlegla nekim prijateljskim nagovorima za ta super-truper sniženja do $70 \%$, pa je onda i ova marama rezultat toga. Jer onda se skupila jedna ekipa žena koje zajedno vježbamo i onda smo išle tamo daleko prema zapadu, u ovaj West Gate na izlet. I onda sam tamo, recimo, trgovala [misli se sa ovim stvarima [pokazuje na maramu] $(\check{Z}, 53)$.

Šta sam ono neki dan, Maji rolšue [kupila u Nami], tu na Trgu više ne možeš, u centru užem nema sportskog dućana di djetetu možeš kupit rolšue. Moraš sjest u auto, otić na izlet i cijeli dan provest u glupom šoping molu $(\check{Z}, 50)$.

Ja jako volim cijeli ritual kupovanja na placu, ja da idem do placa ja moram sjest u auto i 10 minuta voziti do grada, parking platiti u centru grada, ići na plac, jer ga nemam u kvartu, jer volim ići na ribarnicu, jer volim tamo od bakica kupiti grincajg i sve to, to mi je ritual. Znam da, svjesna sam toga da možda i više platim nego da sam to isto kupila u Lidlu ili Mercatoru, ali što se tiče lokaliteta, ja živim na dijelu gdje imam i Lidl i Konzum i Mercator i Getro, tako da imam stvarno izbor (Ž, 39).

Navedena kazivanja kompatibilna su po pitanju nadgradnje potrošačkih praksi individualnim vrijednosnim sudovima. Zadnje kazivanje govori o tome kako su, bez obzira na mjesto stanovanja, potrošačke prakse sudionice vođene vlastitim preferencijama koje nadilaze kriterij praktičnosti. Zatim, iz drugoga kaziva- 
nja jasno se očituje kako je specifikum Name bitno određen pozicijom u središtu grada. No, to kazivanje ne opisuje samo potrošačke prakse povezane s Namom, nego izražava i vrijednosni sud o potrošačkim izletima u trgovački centar, kao i prvo navedeno — da aspekt urbanoga doživljaja mogu prioritizirati i ljudi koji posjeduju automobil. Ne radi se dakle samo o objektivnom značenju mobilnosti, odnosno društvenoj kategorizaciji posjedovanja ili ne posjedovanja automobila — što bi bila klasična ekonomska klasifikacija, nego i o subjektivnom značenju urbanoga iskustva, koje u okviru ekonomije identiteta podrazumijeva takozvane dobitke i gubitke u identitetskoj korisnost. Na taj način potrošački praksa postaje gradivo subjektiviteta ovisno o vrijednosnim orijentacijama pojedinca, ne isključivo prema načelu utilitarnosti.

Iako je ekonomsko načelo korisnosti i dalje prisutno, ono je u novoj ekonomskoj paradigmi ipak identitetski, a ne više isključivo monetarno označeno. To znači prihvaćanje izravnoga utjecaja identiteta na pojedinačno ponašanje, a »taj je utjecaj najočitiji u stvarima koje ljudi čine, a koje ne daju nikakvu ekonomsku korist « (Akerlof i Kranton, 2012, 121). Prihvativši da ljudsko ponašanje često uopće nema ekonomskoga smisla, te mu se nerijetko suprotstavlja, ekonomisti identiteta konačno su odbacili ortodoksnoga homo oeconomicus, te već afirmiranoj marketinškoj psihologizaciji pridodali dinamičke individualne identitete. Afirmirajući time diskurs o potrošačkim mentalitetima, odnosno antropološki rečeno potrošačkim kulturama, s naglaskom na njihovu množinu.

\section{Zaključak}

Izložena analiza pokazala je kako istraživanja ekonomskoga života, odnosno identiteta potrošača, ne govore samo o osobama koje kupuju određene predmete, koriste ili ne koriste određene potrošačke prostore, nego i o mjestu pojedinca u reproduciranju struktura društvene klasifikacije koje nadilaze sferu ekonomske transakcije. Međutim, nastojanje ove analize bilo je prikazati da to nužno ne pretpostavlja subliminalno zavedenoga potrošača, redovito prisutnoga u kritikama suvremenoga društva. Naime, gradivo i izložena tumačenja u usporedbi s ekonomijom identiteta, ocrtavajući refleksivan element objektivizacije kulture, nude nešto afirmativniju interpretaciju, kako na razini tumačenja suvremenoga ekonomskoga života, tako i na razini teorijsko-metodološkoga interdisciplinarnoga približavanja.

Prvo, kroz pojam rekreativne potrošnje prikazano je kako potrošački prostori doista reflektiraju promjene širega društvenoga konteksta. Naracije koje opisuju korištenje proizvoda "bez potpisa" naglašavaju kako je variranje ukusa stupnjevitoga karaktera te potvrđuju kreativnost procesa objektivizacije. Međutim, ekonomija identiteta, zadržavajući ortodoksni model korisnosti, u poimanju identiteta još uvijek ne prepoznaje osobitost kulturne klasifikacije predmeta te nadgradnje individualnim vrijednosnim sudovima. Riječ je o tome da se kulturna klasifikacija u praksama potrošnje oblikuje i kao odbijanje određenih potrošač- 
kih dobara, pa se i ekonomska paradigma potrošačkih identiteta teže snalazi u situaciji u kojoj ekonomska transakcije nije (nužno) mjerilo tumačenja.

Zatim, ne samo da je individualan identitet sadržan u izboru ili odbijanju određenoga proizvoda, nego i u izboru ili odbijanju mjesta potrošnje, koja potom na isti način postaju gradivo subjektiviteta. Utoliko ovdje izloženo narativno gradivo nalaže preoblikovanje strukturalističkoga načela. Naime, strukturalistička maksima kako je kultura ta koja svojim vrijednostima i mehanizmima ograničava i uobličava proces potrošnje, te time potrošnja dobara postaje arena učenja kulture, nužno se nadopunjava kreativnom moći pojedinca koji svojim praksama oblikuje vlastitu potrošačku kulturu. Iz toga proizlazi da potrošnja predstavlja dominantno individualnu praksu procesualnoga karaktera, međutim uz naglasak da pojedinačne kreativne prakse jesu kontestualizirane, odnosno imaju jasne kontekste iz kojih dolaze te u kojima funkcioniraju, ne funkcioniraju ili ih svjesno odbijaju. Naime, ona je zavisna od društvenih struktura, ali nije nužno usklađena s njima, nego uključuje i refleksivan element procesa samoidentifikacije. U okviru ekonomije identiteta taj proces prepoznat je kao kategorija odmjeravanja dobitka i gubitaka u identitetskoj korisnosti.

Začetnici ekonomije identiteta postavili su time pitanje o identitetu, međutim priznavši bez susprezanja kako je razumijevanje koncepta identiteta $u$ ekonomskim analizama još uvijek na početku. Iako ekonomija identiteta znači prihvaćanje izravnoga utjecaja identiteta na pojedinačno ponašanje, ono je još uvijek mjerljivo, odnosno antropološki rečeno strukturalno, a ne procesualno. Kontekstualizacija iskustava sudionika istraživanja ukazuje upravo na procesualnost, na manjkavost univerzalnih značenja, slabost sterotipiziranja, te nužnost pripisivanja performativnoga značenja potrošačkim praksama. U tom smislu, na teorijskoj razini, snaga djelujućega pojedinca za izlazak iz struktura značila bi i mogućnost ostvarivanja utemeljene multidisciplinarnosti, one koja se temelji na razmjeni ne samo apstraktnih ideja, nego konkretnih koncepata i metoda.

\section{Literatura:}

Akerlof, George A.; Kranton, Rachel E. (2012). Ekonomija identiteta: Kako naši identiteti oblikuju naš rad, plaće i blagostanje. Zagreb: Mate.

Akerlof, George A.; Kranton, Rachel. E. (2000). Economics and Identity. Quaterly Journal of Economics, 3, 715-753.

Augé, Marc (2001). Nemjesta: Uvod u moguću antropologiju supermoderniteta. Zagreb: Naklada Društva arhitekata, građevinara i geodeta Karlovac.

Bauman, Zygmunt (1988). Sociology and Postmodernity. Sociological Review, 32(5), 790813.

Bauman, Zygmunt (2007). Collateral Casualities of Consumeris. Jouranl of Consumer Culture, 7(1), 25-56.

Bourdieu, Pierre (2011). Distinkcija: Društvena kritika suđenja. Zagreb: Antibarbarus.

Brstilo, Ivana (2014). Rad nedjeljom: Put u potrošačko društvo? U: Gordan Črpić i Mijo Džolan (ur.), Slobodna nedjelja: Kultura u nestajanju? (str. 81-106). Zagreb: Centar za promicanje socijalnog nauka Crkve.

Certeau, Michael de (2003). Invencija svakodnevice. Zagreb: Naklada MD. 
L. Mihaljević et al., Potrošačka kultura i ekonomija identiteta Obnovljeni život, 2019, 74(2), 217-231

Chaney, David (1983). The Department Store as a Cultural Form. Theory, Culture \& Society, 3, 22-31.

Charmaz, Cathy (2006). Constructing Grounded Theory: A Practical Guide Through Qualitative Analysis. London: Sage.

Čapo Žmegač, Jasna; Gulin Zrnić, Valentina; Šantek, Goran Pavel (2006). Etnologija bliskoga: Poetika i politika suvremenih terenskih istraživanja. Zagreb: Institut za etnologiju i folkloristiku.

Čolić, Snježana (2008). Sociokulturni aspekti potrošnje, potrošačke kulture i društva. Društvena istraživanja, 6, 953-974.

Čolić, Snježana (2013). Suvremena potrošačka kultura neoliberalnog kapitalizma i održivosti: Globalni aspekti. U: Snježana Čolić (ur.), Potrošačka kulura i konzumerizam (str. 11-24). Zagreb: Institut društvenih znanosti Ivo Pilar.

Davis, John Bryan (2011). Individuals and Identity in Economics. New York: Cambridge University.

Douglas, Mary; Isherwood, Baron (1996). The World of Goods: Toward an Anthropology of Consumption. London: Routledge.

Duda, Igor (2010). Pronađeno blagostanje: Svakodnevni život i potrošačka kultura u Hrvatskoj 1970-ih i 1980-ih. Zagreb: Srednja Europa.

Erdei, Ildiko (2008). Antropologija potrošnje: Teorije i koncepti na kraju XX veka. Beograd: Knjižara Krug.

Erdei, Ildiko (2012). Čekajući Ikeu: Potrošačka kultura u postsocijalizmu i pre njega. Beograd: Srpski genealoški centar.

Falk, Pasi; Campbell, Colin (1997). Introduction. U: Pasi Falk i Colin Campbell (ur.), The Shopping Experience (str. 1-15). London: Sage.

Garai, Laszlo (2016). Identity Economics, Indees? A Psychological Introduction. U: Laszlo Garai (ur.), Reconsidering Identity Economics: Human Well-Being and Governance (str. 1-17). Basingstoke: Palgrave Mcmillan.

Gilboa, Itzha (2009). Rational choice. Cambridge, Mass: MIT.

Hromadžić, Hajrudin (2008). Konzumerizam: Potreba, životni stil, ideologija. Zagreb: Jesenski i Turk.

Kotler, Philip (1967). Marketing management: Analysis, planning, and control. New York: Prentice-Hall.

Kotler, Philip (1972). What consumerism means for marketers. Harvard Business Review, 50(3), $48-57$.

Krishna, Aradhna (ur.) (2009). Sensory Marketing: Research on the Sensuality of Products. London: Routledge.

Madison, James (1976). Changing Patterns of Urban Retailing in the 1920's. Bussines and Economic Hystory, 5, 102-111.

Martinović, Maja (2012). Marketing u Hrvatskoj: 55 poslovnih slučajeva. Zagreb: Mate.

Miles, Steven (2006). Consumerism — as a Way of Life. London: Sage.

Miller, Daniel (1993). Material Culture and Mass Consumption. Oxford: Blackwell.

Miller, Daniel (1994). Modernity: An ethnographic approach, Dualism and Mass Consumption in Trinidad. Oxford: Berg.

Miller, Daniel (1995). Consumption and Commodities. Annual Riview of Anthropology, 24, 141-161.

Miller, Daniel; Jackson, Peter; Thrift, Nigel; Holbrook, Beverley; Rowlands, Michael (1998). Shopping, Place, and Identity. London: Routledge. 
Simon, Herbert A. (1955). A Behavioral Model of Rational Choice. The Quarterly Journal of Economics, 69(1), 99-118.

Stanić, Sanja (2013). Trgovački centar kao reprezent potrošačkog društva. U: Snježana Čolić (ur.), Potrošačka kultura i konzumerizam (str. 125-148). Zagreb: Institut društvenih znanosti Ivo Pilar.

Veblen, Thorstein (2008). Teorija dokoličarske klase. Novi Sad: Mediterran.

Vlaović, Milana (2018). Generacijski jaz: Naša robna kuća i njihov shopping mall. Ja sam Milana, 12. lipnja 2018. URL: http://milanavlaovic.hr/generacijskijaz-robnakuca/ ()

Žimbrek, Ivana Mihaela (2017). Uvod u jugoslavensku potrošačku kulturu. Regionalni portal, 18. listopada 2017. URL: https://www.xxzmagazin.com/uvod-u-jugoslavensku-potrosacku-kulturu (02.12. 2018.)

\section{Consumer culture and identity economics}

Consumer mentalities and interdisciplinary approaches

Lucija Mihaljević*, Borna Jaľ̌enjak**

\section{Summary}

The paper aspires to contribute to consumer culture discussions. It focuses on anthropologizing orthodox economic models through the paradigm of identity economics as portrayed in economic theory. The emphasis is on a comparison between the economics definition of identity and anthropological concepts. The conceptual framework of the analysis is based on anthropological structuralism - according to which tastes become a form of social differentiation - and also on the theoretical perspective of the objectification of culture in the global context. Empirical ethnographic material on consumer practices and experiences is examined using qualitative methodology in accordance with the rules of grounded theory. Expressive dimensions of the consumer culture are examined from a diachronic perspective of Croatian society starting from the second half of the twentieth century until today. The scope of this analysis includes the interrelationship between consumer practices with reference to a dominant department store during the socialist era and the same in modern shopping malls. The authors question structuralist principles, arguing in favor of the creative character of the identification processes. In illustrating narrative examples, they demonstrate how consumption can become a matter of subjectivity regardless of the economic transaction being realized or not. Research shows how material objects become symbols of individual identity both for those who use them and those who reject them. Finally, the paper affirms the benefits of a methodological shift in the direction of interdisciplinarity, i.e. the identity-based interpretation of consumer society and the necessity of attributing performative meaning to economic practices.

Key words: identity economics, consumer culture, identification processes, socioeconomic structure, objectification, department store, shopping mall

* Lucija Mihaljević, Ph.D., Post-Doctorand. Catholic University of Croatia. Address: Ilica 242, 10000 Zagreb, Croatia. E-mail: lucija.mihaljevic@unicath.hr

* Borna Jalšenjak, Ph.D., Senior Lecturer. Luxembourg School of Business; Zagreb School of Economics and Management. Address: 19 Rue Eugene Ruppert L-2453, Luxembourg; Jordanovac 110, 10000 Zagreb, Croatia. E-address: bjalsen@zsem.hr 